\title{
AS COMPLEXIDADES INERENTES AO TEMA "MUDANCCAS CLIMÁTICAS": DESAFIOS E PERSPECTIVAS PARA O ENSINO DE FÍSICA
}

\author{
Danielle Aparecida dos Reis* \\ Luciano Fernandes Silva** \\ Newton Figueiredo***
}

RESUMO: A articulação entre a física e a temática ambiental apresenta oportunidades para a construção de práticas educativas que privilegiam o tratamento das controvérsias e das complexidades associadas aos temas ambientais, como ocorre com o fenômeno das mudanças climáticas. Neste ensaio teórico destaca-se que a natureza complexa desse fenômeno climático favorece o surgimento das controvérsias, o que proporciona aos professores da Educação Básica possibilidades para o tratamento educativo diferenciado desse tema. De modo especial, apresentam-se e discutem-se alguns aspectos, do ponto de vista da física, relativos à complexidade inerente ao tema "mudanças climáticas", a fim de contribuir para uma reflexão voltada para a natureza dessas complexidades e para suas potencialidades educativas.

Palavras-chave: Ensino de física. Complexidade. Mudanças climáticas.

\section{LAS COMPLEJIDADES INHERENTES AL TEMA "CAMBIOS CLIMÁTICOS": DESAFÍOS Y PERSPECTIVAS PARA LA ENSEÑANZA DE LA FÍSICA}

Resumen: La articulación entre la física y la temática ambiental presenta oportunidades para la construcción de prácticas educativas que privilegian el tratamiento de las controversias y de las complejidades asociadas a los temas ambientales, como ocurre con el fenómeno de los cambios climáticos. En este ensayo teórico, se destaca que la naturaleza compleja de este fenómeno climático favorece el surgimiento de controversias, que proporcionan posibilidades para el tratamiento educativo diferenciado de este tema a los profesores de la Educación Básica. De modo especial, se presentan y se discuten algunos aspectos, del punto de vista de la física, relativos a la complejidad inherente al tema "cambios climáticos", con el fin de contribuir para una reflexión acerca de la naturaleza de esas complejidades y para sus potencialidades educativas.

Palabras clave: Enseñanza de la física. Complejidad. Cambios Climáticos.

\author{
* Doutoranda em Educacão pela \\ Universidade Estadual Paulista Júlio \\ de Mesquita Filho (Unesp-Rio Claro). \\ E-mail: dani_aparecidareis@yahoo. \\ com.br \\ ** Doutor em Educação pela \\ Universidade Estadual Paulista \\ Júlio de Mesquita Filho (UNESP). \\ Atualmente é professor Adjunto \\ Doutor do Departamento de Física e \\ Química da Universidade Federal de \\ Itajubá (UNIFEI). \\ E-mail: lufesilv@gmail.com \\ *** Doutor em Astrofísica pelo \\ Instituto Nacional de Pesquisas \\ Espaciais (INPE). Atualmente é \\ professor de ensino superior da \\ Universidade Federal de Itajubá. \\ E-mail: newton@unifei.edu.br
}


COMPLEXITIES INHERENT TO THE SUBJECT "CLIMATE CHANGE": CHALLENGES AND PROSPECTS FOR PHYSICS TEACHING

Abstract: The link between Physics and environmental issues present opportunities tobuild educational practices centered on dealing with controversies and complexities associated with environmental issues, such as the phenomenon of climate change. In this theoretical essay we point out that the complex nature of this climatic phenomenon favors the emergence of controversies, which gives elementary school teachers many educational opportunities to develop a non-conventional approach to the theme. In particular, this work presents and discusses some aspects, from the point of view of Physics, concerning the complexity related to the issue of climate change in order to contribute to the debate focused on the nature of these complexities and their educational potential.

Keywords: Physics Teaching. Complexity. Climate change. 


\section{INTRODUÇÃO}

O período histórico atual parece estar marcado por preocupações ligadas aos temas ambientais, de tal modo que diferentes grupos sociais organizados têm voltado a atenção para problemas dessa natureza. Soma-se a isso a ampla divulgação nos meios de comunicação em massa das discussões relativas às questões ambientais. Esses fatos têm incentivado a elaboração de trabalhos na Educação Básica que contemplam essa temática. Há diversas possibilidades de se abordar questões relativas ao meio ambiente nas propostas educativas, e uma delas, em especial, se dá por meio do seu tratamento a partir de controvérsias e de complexidades que lhe são inerentes.

Entende-se que o trabalho educativo com a temática ambiental deveria envolver de maneira articulada a maioria das disciplinas que compõem o currículo do ensino básico, inclusive a disciplina de física, tendo em vista que esta oferece subsídios para a compreensão de vários aspectos da complexidade associada a esse tema.

Nesse sentido, um dos meios para que os professores de física trabalhem com aspectos da temática ambiental na organização e na execução de atividades de ensino está vinculado à ideia de abordar o tema das mudanças climáticas a partir do tratamento de complexidades e de controvérsias de diferentes naturezas a ele associadas. Aliás, observa-se que alguns trabalhos educativos relacionados com controvérsias que giram em torno dos fenômenos climáticos vêm sendo publicados na área de ensino de ciências nos últimos anos (XAVIER; KERR, 2004; VIERIA; BAZZO, 2007; PINA; SILVA; OLIVEIRA JÚNIOR, 2010; CASAGRANDE; SILVA JÚNIOR; MENDONÇA, 2011; REIS; SILVA, L. F.; SILVA, L. M., 2011; BARBOSA; LIMA; MACHADO, 2012).

Alguns desses trabalhos abordam controvérsias de natureza científica relacionadas ao tema das mudanças climáticas. Todavia, é relevante indicar que várias dessas controvérsias se devem ao fato de que são elaboradas diferentes hipóteses sobre as causas, os possíveis efeitos e as diferentes possibilidades de amenizar ou até mesmo reverter as consequências das mudanças climáticas. Estas, por sua vez,

[...] constituem-se menos de relações de causalidade ou por construções conceituais e mais pela própria visão de ciência que, para lidar com sistemas complexos, precisa rever os modelos reducionistas, ou o paradigma da simplificação, e compreender o sentido dos resultados, das medidas e das previsões dos modelos utilizados (RIBEIRO; KAWAMURA, 2014, p. 164).

$\mathrm{Na}$ perspectiva das autoras, reconhecer a complexidade do fenômeno apresenta elementos para que concepções epistemológicas sobre ciência e produção do conhecimento científico possam ser reformuladas, já que muitas são pautadas no determinismo e na linearidade. Nessa linha de raciocínio destaca-se que estudos e investigações realizados a partir da segunda metade do século XX 
apontam que a compreensão determinista, simplificadora, fragmentada da realidade deve ser superada.

Por outro lado, também cabe ressaltar que as decisões econômicas, políticas e sociais relativas ao fenômeno caracterizam um jogo de interesses complexo e conflituoso, o que possibilita a identificação de controvérsias políticas e econômicas associadas diretamente com a tomada de decisão sobre as mudanças climáticas.

Desse modo, pode-se indicar que os fenômenos climáticos emergem em um campo complexo e que envolvem, além da dinâmica climática terrestre, a interação entre o ser humano e a natureza, as concepções políticas dos governantes que se adequam ou não às medidas de mitigação, aos ganhos econômicos que estão por trás das negociações de redução das emissões de combustíveis fósseis (principal medida de mitigação apresentada) e a tantas outras questões (VEIGA; VALE, 2007).

Nessa perspectiva apresentam-se reflexões neste trabalho que apontam para o fato de que a Física auxilia o reconhecimento de alguns aspectos da complexidade inerentes aos fenômenos climáticos. Ao mesmo tempo, destaca-se que a abordagem das mudanças climáticas a partir de suas controvérsias e de seus aspectos complexos possibilita aos sujeitos envolvidos no processo de ensino e aprendizagem o entendimento das subjetividades, das incertezas, dos conflitos, dos valores, dos questionamentos metafísicos e políticos relacionados a essa questão ambiental.

Pensando nessas questões, propõe-se neste ensaio teórico uma reflexão sobre possibilidades de planejar e executar atividades educativas envolvendo temas socioambientais de grande repercussão pública e conteúdos específicos da física. De modo especial, apresentam-se e discutem-se algumas questões, do ponto de vista da física, relativas a alguns aspectos das complexidades inerentes ao fenômeno das mudanças climáticas, buscando contribuir para uma reflexão voltada para a natureza desse fenômeno e para suas potencialidades educativas na Educação Básica.

\section{Complexidades, controvérsias e mudanças climáticas}

A complexidade apresenta-se como uma forma de olhar para o mundo e, a partir dela, pode-se entender a existência de algumas controvérsias relacionadas aos temas ambientais, em especial ao das mudanças climáticas.

Morin (2007, p. 69) define que uma realidade complexa diz respeito "[...] à incapacidade de ter certeza de tudo, de formular uma lei, de conceber uma ordem absoluta". Para o autor, reconhecer uma realidade complexa significa "[...] compreender que jamais poderemos escapar da incerteza e que jamais poderemos ter um saber total, apresentando assim maneiras diversificadas de se compreender a realidade".

Por esse motivo, de acordo com o autor referenciado, frente à realidade complexa, torna-se uma tarefa difícil evitar as contradições, o que pode caracterizar o surgimento de controvérsias como, por exemplo, aquelas decorrentes da 
limitação de uma determinada visão de ciência para lidar com sistemas complexos.

Para Prigogine (1996), a partir do momento em que essa realidade complexa for compreendida, será reconhecida uma ciência que permite a vivência da criatividade humana, que não se limita à simplificação e à idealização de determinadas situações, mas que coloca o humano diante da complexidade do mundo real.

Sob a égide das teorias complexas, apresenta-se uma nova maneira de compreensão das organizações sistêmicas, denominadas sistemas complexos. A partir da definição de que a associação combinatória de elementos diferentes constitui um sistema, entende-se que toda a realidade conhecida (átomos, moléculas, célula, organismo, sociedade, natureza) pode ser concebida como tal. Essa associação é caracterizada como interdependente, ou seja, pequenas modificações em um dos elementos podem causar grandes modificações no sistema como um todo (WATANABE-CARAMELLO, 2012).

Esse novo paradigma apresenta o mundo como "um todo integrado", e não como a adjunção de partes separadas, visto que reconhece a interdependência de todos os componentes dessa organização. A complexidade pressupõe o entendimento do real em sua totalidade, o que não implica a justaposição de localidades separadas (nem a totalidade, nem a localidade são preponderantes uma sobre a outra). Ainda pode ser caracterizada por um ciclo gerador no qual os produtos e as consequências são produtores e originadores daquilo que produzem, o que significa que a causa age sobre o efeito e o efeito age sobre a causa (MORIN, 2007).

Uma organização sistêmica pode ser composta por vários outros sistemas menores, que juntos formam hierarquias, o que implica diferentes níveis de organização de complexidade, ou seja, em cada um desses níveis os fenômenos observados possuem propriedades e leis que podem não se apresentar no nível anterior. Entretanto, é importante que se tenha a clareza de que esses diferentes níveis de organização “[...] estão amplamente conectados, de modo que entender todas as interações decorrentes desse sistema é tarefa limitada; e as interações podem ocorrer em espaços e tempos distintos, mas que de alguma forma interferirá no sistema global" (WATANABE-CARAMELLO, 2012, p. 228).

O clima é um exemplo de um sistema que pode ser caracterizado como complexo, sujeito à interferência de diversas variáveis (naturais e antropogênicas), o que é responsável por caracterizá-lo pela sua não linearidade, dinamicidade, instabilidade e imprevisibilidade. Nesse caso, lidar com fenômenos ligados ao clima significa focar possibilidades em vez de certezas absolutas. A consideração das incertezas, independente do lado pelo qual se olha o problema, oferece espaço para o surgimento de dissensos sobre determinados pontos a elas associados.

Nessa perspectiva, entende-se que o reconhecimento da existência de controvérsias ligadas ao tema das mudanças climáticas dar-se-á de modo mais efetivo se o meio natural, o científico, o social, o econômico e o político em que tais eventos ocorrem forem entendidos segundo um olhar pautado pela complexidade.

A partir dessas considerações, entende-se que a caracterização das complexidades associadas aos fenômenos climáticos também pode ser abordada em 
algumas situações educativas. Segundo Watanabe-Caramello e Kawamura (2010), para uma compreensão mais realista das questões climáticas, é necessário que nas práticas educativas o sistema climático seja tratado como um sistema dinâmico, aberto e fora do equilíbrio. Pensando nessas características do fenômeno, compreende-se que as leis da termodinâmica possam fornecer subsídios para um entendimento mais abrangente das mudanças climáticas, caracterizando, assim, parte da sua complexidade.

Nesse sentido, compreende-se que alguns aspectos da Teoria da Complexidade, enunciados por Edgar Morin (2007) e Ilya Prigogine (1996), sejam considerados essenciais para o reconhecimento das complexidades inerentes ao fenômeno das mudanças climáticas.

Diante desse contexto destacam-se a seguir algumas complexidades específicas associadas ao fenômeno das mudanças climáticas, buscando realizar articulações com a física.

\section{Complexidades e mudanças climáticas}

É interessante observar que representações sobre a natureza foram modificadas ao longo da história da humanidade. Parte dessas modificações está particularmente atrelada à forma como a ciência modela e descreve a realidade. De modo geral, destaca-se a interpretação da realidade propiciada pela ciência moderna, caracterizada pela perspectiva do mecanicismo que objetivava a busca de leis simples para explicar o funcionamento do universo.

Prigogine e Stengers (1984, p. 32) apontam que a natureza, a partir dessa perspectiva, é descrita com o auxílio de uma linguagem matemática única e decifrável pela experimentação, do mesmo modo que apresenta um mundo homogêneo, já que a experimentação local descobre uma verdade geral: "[...] os fenômenos simples que a ciência estuda podem desde logo entregar a chave do conjunto da natureza, cuja complexidade não é mais que aparente: o diverso reduz-se à verdade única das leis matemáticas do movimento".

Essa visão simplificadora, determinista e reducionista da ciência vai, ao longo do século XX, sendo incorporada por uma visão epistemológica mais abrangente. Segundo Fiedler-Ferrara (2003), a partir da segunda metade do século XX emerge o que alguns autores chamam de renúncia à prioridade epistemológica das categorias simplicidade, ordem e regularidade, a favor de categorias como complexidade, desordem e caoticidade. Porém, segundo o autor, "[...] note-se que se fala em termos de 'renúncia à prioridade epistemológica', o que não significa que simplicidade, ordem e regularidade sejam suprimidas, mas sim incorporadas numa moldura epistemológica mais larga" (FIEDLER-FERRARA, 2003, p. 3).

Levando em consideração esses apontamentos, entende-se que a Termodinâmica do não equilíbrio e a teoria da complexidade, representantes dessa nova perspectiva epistemológica, apresentam subsídios para outra forma de compreender alguns fenômenos da natureza e fornecem vários elementos para que seja possível desenvolver uma compreensão mais abrangente sobre a realidade. 
De maneira especial, tomando como base os referenciais de Ilya Prigogine (1996) e Edgar Morin (2007), são apresentados alguns aspectos que apontam para as complexidades relacionadas aos fenômenos climáticos, entre eles: instabilidade, probabilidade, irreversibilidade e organizações sistêmicas.

Prigogine (2002) apresenta um esquema da relação entre os conceitos acima destacados: instabilidade $\rightarrow$ probabilidade $\rightarrow$ irreversibilidade. De acordo com o autor, essa relação justifica-se levando em conta que:

A instabilidade e o caos obrigam-nos a passar a um esquema probabilístico (abandono das trajetórias na mecânica clássica e das funções de onda na mecânica quântica), o qual nos leva a estudar o operador de evolução correspondente, que nos permitirá esclarecer a ruptura da simetria temporal e, portanto, a irreversibilidade. (PRIGOGINE, 2002, p. 42)

Uma forma de articular essas ideias com o sistema climático ocorre a partir da concepção de que a Terra pode ser modelada como um grande sistema termodinâmico. Nesse modelo, o clima pode ser entendido como uma sucessão de fenômenos irreversíveis, o que faz com que a entropia do planeta aumente à medida que o tempo passa.

Para Watanabe-Caramello (2012, p. 122), a complexidade do sistema climático pode ser identificada ao se levar em consideração os diferentes fatores cujas relações interferem diretamente na realidade climática. Ao voltar o olhar para a questão climática, a autora menciona que é fundamental ponderar diversos pontos, como os "[...] microclimas (subsistemas), distintos relevos, características ecológicas regionais etc.; além das influências de fatores externos, como a variação solar. Nesse contexto, ainda é importante levar em consideração mudanças sofridas graças às eras glaciais".

O sistema climático também está sujeito à influência da atividade solar, da atmosfera, dos oceanos, do gelo, das florestas, das superfícies e das atividades humanas. Desse modo, o fenômeno das mudanças climáticas pode ser compreendido levando-se em conta a dinamicidade, a instabilidade e o caráter probabilístico a ele associados.

A partir do exposto, aponta-se que as teorias sistêmicas complexas associadas aos princípios termodinâmicos podem oferecer aos professores de física subsídios para a compreensão da dinâmica climática terrestre, visto que as suas principais características (instabilidade, irreversibilidade, imprevisibilidade, interação sistêmica) podem ser identificadas com maior facilidade quando apoiadas nesses conceitos.

Para este estudo toma-se como base a Termodinâmica do não equilíbrio. Prigogine (2002, p. 79-80) escreve que a:

[...] entropia e a física do não equilíbrio nos ensinam algo de fundamental acerca da estrutura do universo: a irreversibilidade torna-se um elemento essencial para a nossa descrição do universo, portanto devemos encontrar a sua expressão nas leis fundamentais da dinâmica. A condição essencial é que a descrição microscópica do universo seja feita por meio de sistemas dinâmicos instáveis (grifo nosso). 
Também é relevante indicar que a Terra pode ser concebida como um sistema termodinâmico complexo e aberto, já que troca matéria e energia com o espaço. Esse sistema não é isolado, pois recebe e emite radiação eletromagnética. A radiação recebida vem principalmente do Sol e tem um espectro aproximado de um corpo negro com intensidade máxima no visível. A radiação emitida, por sua vez, tem intensidade máxima na região do infravermelho. Esse sistema envolve vários elementos, que estão agrupados em subsistemas, com comportamentos particulares e que estão em constante interação, o que é responsável por formar novas estruturas capazes de gerar mudanças na configuração inicial. Esses subsistemas também são abertos, tanto para massa, quanto para energia. Essa constante interação é responsável por causar flutuações nesse sistema, o que o caracteriza como um sistema dinâmico variável e instável.

É importante apontar que as condições climáticas do planeta Terra sempre foram instáveis, o que pode ser constatado mediante o estudo da história geológica. A partir da análise do histórico da variabilidade climática terrestre, é possível indicar que ocorreram diversas variações na temperatura da superfície terrestre, intercalando épocas com temperaturas mais elevadas (Medieval Climate Optimum) e períodos com temperaturas mais reduzidas (Little Ice Age) (AKASOFU, 2006). Isso evidencia que "o clima não é estático, mas sim dinâmico; ao longo de milhões de anos de existência da Terra, ele tem mudado muitas vezes em resposta a causas naturais" (OLIVEIRA; VECHIA, 2009, p. 948).

Nessa perspectiva, a análise do histórico das variações climáticas sofridas pelo planeta é outro aspecto que revela a complexidade do sistema climático. Nesse sentido, segundo Watanabe-Caramello (2012, p. 234), o estudo dessa característica complexa permite, entre outros aspectos, reconhecer "[...] que a vida na Terra tem uma história evolutiva, diversificando-se e especializando-se e modificando o próprio ambiente terrestre; considerar que as intervenções dos seres humanos têm uma longa história”.

Outro ponto importante da análise sobre as complexidades inerentes aos fenômenos climáticos está voltado para o estudo do sistema Terra-Atmosfera. É relevante indicar que parte da instabilidade climática se origina da interação entre os fenômenos que são responsáveis por causar variações na energia recebida do Sol ou na energia que é retida na atmosfera, o que causa interferência direta no balanço energético do sistema Terra-Atmosfera. Nesse sentido, é possível identificar variáveis tanto naturais quanto antrópicas que podem causar interferências na variação de energia solar recebida pela Terra, o que resulta em grandes variações climáticas.

A modificação da quantidade de radiação solar que é recebida pelo planeta implica diretamente algumas mudanças climáticas. Os fatores responsáveis por causar tais mudanças estão diretamente ligados à órbita da Terra e à produção de energia solar. Esses fatores são denominados externos, já que não constituem o sistema Terra-Atmosfera, apesar de manter relação direta com ele.

Um fator externo importante é descrito pela Teoria de Milankovich 
(HAYS et al., 1976). De acordo com essa teoria, a intensidade da radiação solar que atinge a superfície terrestre varia ao longo do tempo em decorrência de alterações periódicas em três parâmetros: a precessão do eixo de rotação, a variação da inclinação do eixo em relação ao plano orbital e as alterações na excentricidade da órbita.

Outro fator externo que pode ser mencionado é a variação na produção de energia solar, correlacionada com a variação no número de manchas solares (SAMPAIO; MARENGO; NOBRE, 2008).

Deve-se, ainda, lembrar que, além da radiação emitida pelo Sol que alcança a superfície terrestre, há também o vento solar composto de partículas carregadas como prótons e elétrons. Esse vento interfere na atmosfera alterando a quantidade de partículas do sistema, incluindo assim mais uma variável a ser considerada.

Por outro lado, podem ser identificados outros fenômenos que, se modificados, podem causar maior/menor reflexão da energia solar incidente (menor/ maior energia absorvida) ou maior retenção dessa energia na atmosfera (maior energia absorvida pela atmosfera e reemitida para a superfície terrestre). Esses são os fatores internos que são responsáveis por causar variações diretas no balanço energético.

Em relação aos fatores internos pode-se dizer que são caracterizados pelos fenômenos responsáveis por causar variações nos constituintes do sistema Terra-Atmosfera e que, em consequência, causam variações no balanço energético. É importante ressaltar que esses fatores podem tanto ser de origem natural quanto de origem antrópica.

$\mathrm{O}$ albedo $^{2}$ pode sofrer variações através da modificação de diversos fatores que são responsáveis por grande parte da reflexão de energia solar incidente na Terra. Entre eles destacam-se as mudanças na cobertura da superfície terrestre e a variação na concentração de nuvens e de aerossóis (SAMPAIO; MARENGO; NOBRE, 2008).

Outro fenômeno que sofre constantes variações e que influi de maneira direta no balanço energético é o efeito estufa. O efeito estufa é um fenômeno natural que envolve processos de interação de radiação eletromagnética com várias moléculas que compõem a atmosfera, genericamente conhecidos como gases estufa. Entre eles pode-se citar o vapor d'água, o dióxido de carbono, o metano, o óxido nitroso, o ozônio, os clorofluorcarbonetos (CFCs) e os hidroclorofluorcarbonetos (HCFCs).

Essas moléculas são responsáveis por absorver boa parte da radiação na faixa de frequências do infravermelho que é emitida pela superfície terrestre e, em seguida, reemitir essa radiação de volta para a superfície, aquecendo-a (XAVIER; KERR, 2004; SILVA et al., 2009).

Argumenta-se que, ao longo do tempo, a composição química da atmosfera terrestre vem sendo modificada, tanto por fenômenos naturais quanto pela intervenção antrópica. Essas modificações podem provocar variações na intensidade do efeito estufa. 
Ressalta-se ainda que a inter-relação existente entre os fenômenos que constituem o sistema climático é responsável por caracterizar tanto a sua variabilidade histórica, quanto por apresentar uma variedade de possíveis futuros para as mudanças climáticas. Existem diferentes probabilidades de ocorrência de diversas consequências a partir da interação entre as variáveis internas e externas ao sistema Terra-Atmosfera.

Nesse momento é interessante acentuar que algumas controvérsias associadas às origens e às causas das mudanças climáticas atuais estão diretamente relacionadas com a tentativa de avaliar o peso dessas variáveis internas e externas ao sistema Terra-Atmosfera nos feedbacks que determinam uma eventual resposta do sistema climático.

Segundo Ribeiro e Kawamura (2014, p. 164), controvérsias científicas envolvendo os temas ambientais derivam, frequentemente, de processos de medidas das grandezas envolvidas e, "embora cada processo possa estar cientificamente correto, pode-se verificar resultados diferentes, enquanto tomam-se por base hipóteses também diferentes, não compartilhadas por todos os cientistas".

Nessa perspectiva, as autoras indicam que a modelização dos fenômenos climáticos, por exemplo, pauta-se pela escolha e pela seleção de parâmetros e condições altamente complexos, cuja natureza das variações não pode ser determinada previamente e

Com isso, fica claro que não há exatamente controvérsias científicas, no sentido mais epistemológico, que se refere à natureza de conceitos, mas a utilização de uma compreensão dos sistemas e ambientes da Terra, locais ou globais, que não leva em conta, na discussão de suas medidas e resultados, o fato de se tratar de sistemas complexos. (RIBEIRO; KAWAMURA, 2014, p. 164)

$\mathrm{Na}$ figura 1 busca-se destacar as diversas correlações existentes entre os componentes do sistema climático, bem como a diversidade de causas e efeitos que devem ser contabilizados no estudo de um modelo climático global. Essa figura indica a existência de uma grande "organização sistêmica" entre a atmosfera, a litosfera, a hidrosfera e a biosfera, sendo que as setas entre elas indicam a existência de uma inter-relação entre as mesmas. Focando os estudos apenas sobre a atmosfera, podem-se identificar alguns fatores que interferem na quantificação da energia recebida e emitida pelo planeta, um dos fatores que indicam sua complexidade. 
FIGURA 1 - Fenômenos relacionados às mudanças climáticas

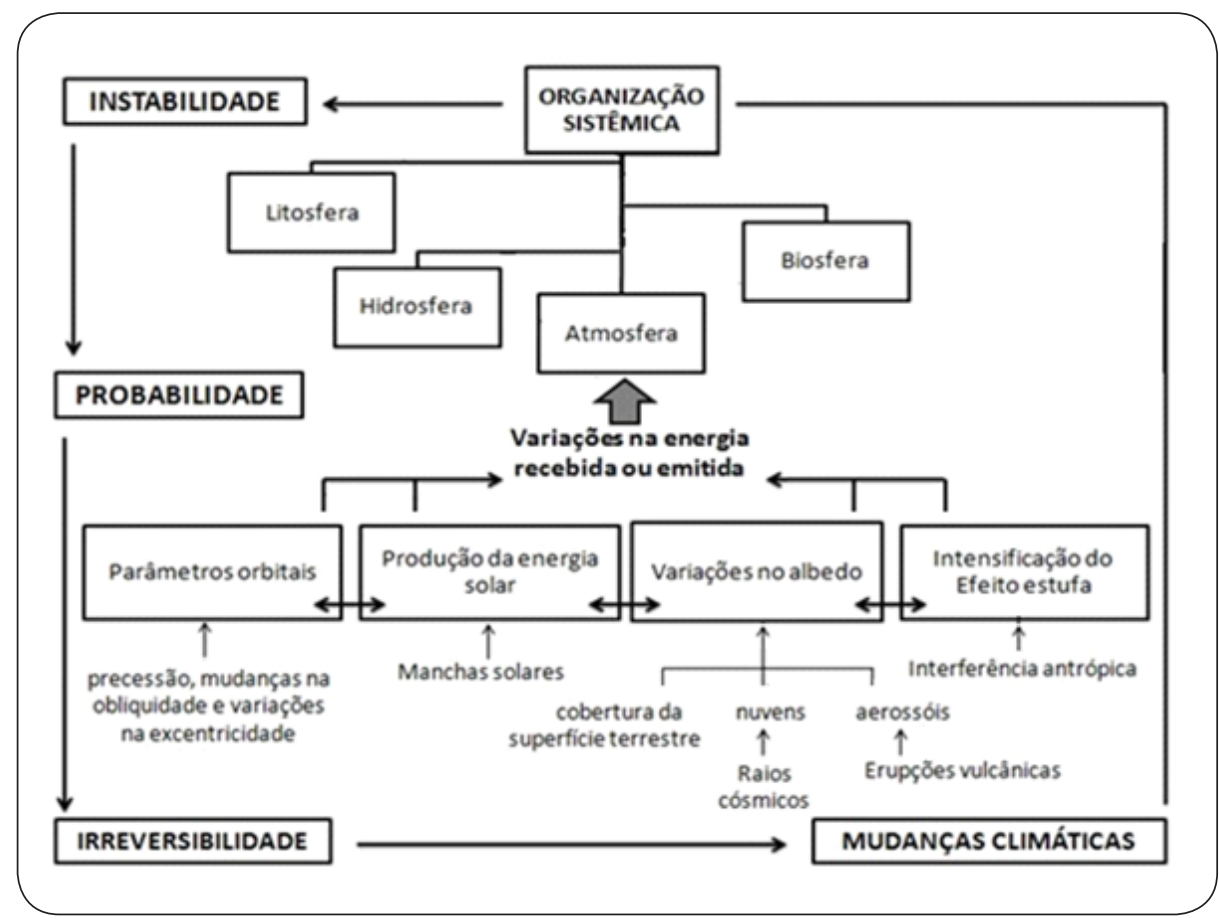

Fonte: REIS, 2013

Entre esses fatores (variação dos parâmetros orbitais, da produção de energia solar, do albedo e a intensificação do efeito estufa) identificam-se outras inter-relações existentes entre eles e outros fenômenos (tanto naturais, quanto antrópicos) que interferem no curso das mudanças no clima. Todos esses fenômenos estão inseridos em um grande sistema complexo caracterizado pela instabilidade, pela probabilidade e pela irreversibilidade.

Destaca-se, também, que o entendimento da Terra como um sistema termodinâmico remete ao conceito de irreversibilidade. Como já mencionado, os fenômenos climáticos podem ser descritos como uma sucessão de fenômenos não reversíveis, o que provoca o aumento da entropia do planeta, evoluindo sempre em um único sentido.

Desse modo, também é possível conjecturar que a questão climática não constitui um processo que seja reversível no tempo. Um sistema termodinâmico que passa por um processo irreversível nunca retorna ao seu estágio inicial com as mesmas características apresentadas antes da intervenção. Ou seja, é razoável supor que, mesmo que fossem freadas totalmente as emissões de gases poluentes, a atmosfera não voltaria a apresentar a mesma composição e o mesmo comportamento de antes da deposição desses gases. De acordo com Watanabe-Caramello (2012, p. 223): “[...] as mudanças nos regimes dos sistemas naturais nunca retornarão ao ponto de partida. Em outras palavras, ao perceber que quaisquer que 
sejam as ações posteriores ao acontecimento, que pode ser um desmatamento ou despoluição, o sistema não retorna ao seu ponto original”.

Também é relevante mencionar que essa irreversibilidade é mais um aspecto da natureza complexa do fenômeno das mudanças climáticas. Para Prigogine (2002, p. 83) existe: “[...] um laço íntimo entre irreversibilidade e complexidade. Quanto maiores os níveis de complexidade (química, vida, cérebro), mais evidente é a seta do tempo. Isso corresponde perfeitamente ao papel construtivo do tempo, tão evidente nas estruturas dissipativas".

Essa complexa "teia de relações" coloca para todos a perspectiva do limite do determinismo científico. Nesse sentido, não é possível prever com exatidão o comportamento climático terrestre. Porém, isso não significa que a ciência não possa apresentar cenários futuros que orientem processos de tomada de decisão, o que indica a possibilidade de tratar regiões com características semelhantes usando as leis da termodinâmica para fazer possíveis previsões para a evolução desse sistema.

É imprescindível que se tenha clareza de que essas previsões são passíveis de dúvidas e de incertezas, já que, além da interferência do ser humano sobre a natureza, existem outros fenômenos naturais que se encarregam de causar mudanças inesperadas no clima. Essa característica aponta para a necessidade de que se olhe não apenas para as consequências como variáveis controladas, embasadas em modelos simplificadores, mas sim para o processo como um todo.

Entretanto, embora não seja possível ter certeza da amplitude que as alterações climáticas alcançarão e dos impactos causados por elas, também não é plausível afirmar que elas não irão se concretizar, visto que se convive frequentemente com o risco. De acordo com Jacobi et al. (2011, p. 136), é importante que exista a clareza em relação "[...] aos efeitos e vulnerabilidades a que todos estamos expostos diante das mudanças climáticas globais”.

Diante dessa incerteza, pensando no fato de que se essas consequências climáticas realmente vierem a se concretizar, “[...] essas poderiam trazer grandes e irreversíveis problemas ambientais, sociais e econômicos" (OLIVEIRA; VECCHIA, 2009, p. 951). Por esse motivo, muitos preferem seguir o princípio da precaução, “[...] segundo o qual atividades capazes de causar danos graves ou irreversíveis ao meio ambiente devem ser restringidas, antes que haja uma certeza científica absoluta de seus efeitos" (JURAS, 2008, p. 40).

A partir dessas considerações, o fenômeno ganha dimensões muito discutidas em outras esferas além da científica, posto que aderir às medidas de mitigação sugeridas por vários grupos sociais organizados, como, por exemplo, a redução do $\mathrm{CO}_{2}$ depositado na atmosfera a partir da queima de combustíveis fósseis, implica rever convicções políticas e valores que fundamentam a forma como muitas sociedades estão organizadas, ou seja, implica rever o American way of life. $\mathrm{O}$ estilo de organização social representado pelo modelo norte-americano se apresenta incompatível com o debate em torno da sustentabilidade, tratada nas suas dimensões ambiental, social, política, econômica e cultural. 
Esse cenário envolve discussões que vão além do âmbito científico, o que fornece elementos essenciais para a contextualização e a problematização do tema em aulas de ciências, ou de física de maneira particular.

Entende-se que há vários caminhos nos quais seja possível abordar os diferentes aspectos relativos às complexidades de temas socioambientais como as mudanças climáticas. Nesse sentido, a abordagem das complexidades inerentes aos fenômenos socioambientais parece ser um caminho potencialmente criativo quando se pensa em trabalhos educativos diretamente ligados à física. A partir desse apontamento, apresentam-se a seguir alguns aspectos relativos às articulações entre a complexidade, os temas controversos e o ensino de física.

\section{Articulações entre complexidade, 0 tema "mudanças climáticas" e 0 ensino de física}

As considerações apresentadas até o momento apontam para algumas possibilidades de abordar o tema "mudanças climáticas" em aulas de ciências a partir do tratamento de controvérsias e complexidades associadas a ele. De maneira específica, entende-se que o campo da física oferece um espaço propício para tratar as complexidades e as controvérsias inerentes a esse tema.

As discussões sobre o tema "mudanças climáticas" atualmente têm grande destaque na sociedade, sendo que as informações sobre este são divulgadas principalmente pelos meios de comunicação em massa. Porém, muitos discursos elaborados por uma parte da mídia em relação a esse tema contêm equívocos conceituais e apresentam abordagens sensacionalistas, fato que acaba por privilegiar uma visão exclusivamente catastrófica e determinista em relação ao fenômeno.

Aponta-se neste trabalho que a abordagem desse tema no ensino básico possibilita ao professor trabalhar em sala de aula os limites dessa perspectiva determinista a partir de um trabalho educativo voltado para temáticas socioambientais.

Entretanto, de acordo com Santos, Carvalho e Levinson (2014, p. 201), a temática ambiental tem sido pouco explorada na disciplina de física. Ainda segundo os autores,

[...] as análises quanto à incorporação da temática ambiental pelas escolas têm indicado, como bastante comum, a tendência em atribuir-se às disciplinas de Ciências da Natureza e Geografia no Ensino Fundamental e de Biologia e Geografia no Ensino Médio a responsabilidade maior por esta tarefa.

Todavia, como já explorado neste ensaio, a abordagem de aspectos da temática ambiental em aulas de física proporciona o tratamento de conteúdos específicos dessa área do conhecimento e, sobretudo, de considerações sobre aspectos da natureza da ciência. Também é indicada a possibilidade de incorporar ao ensino de física a promoção da problematização da relação entre o ser humano e a natureza, possibilitando a discussão acerca dos valores que sustentam a cultura capitalista. A problematização dos valores que sustentam o estilo de vida das sociedades atuais deveria, também, ser um dos objetivos do ensino de ciências que incorpora a discussão da temática ambiental. Nesse caso, é necessário problematizar 
a lógica centrada no consumismo e no individualismo, em que prevalecem interesses privados em detrimento de interesses coletivos, sobretudo por meio da prática de atividade de competição entre indivíduos e/ou grupos (SANTOS; CARVALHO; LEVINSON, 2014).

Especificamente do ponto de vista dos conceitos da física, o trabalho com o tema "mudanças climáticas" permite aos professores o desenvolvimento de temas como, por exemplo, "conservação de energia", "espectro da radiação eletromagnética", "radiação de corpo negro" (emissão e absorção), "dilatação térmica e temperatura”, entre outros. O trabalho específico com conceitos de dissipação de energia e de entropia contribui para que seja dado nas aulas de física o destaque para uma realidade ambiental complexa e controversa.

Em outra perspectiva, a física oferece vários subsídios para que se possam compreender de maneira correta alguns conceitos científicos que remetem às mudanças climáticas. Pina, Silva e Oliveira Júnior (2010) apresentam que os desvios de temperatura, a diminuição ou o aumento do albedo planetário, as variações na circulação atmosférica e oceânica, as mudanças dos parâmetros orbitais da Terra, ou ainda algumas variações na produção de energia solar, apenas serão compreendidos de forma mais abrangente se forem levados em conta os conhecimentos ligados à física.

Além dessas considerações ligadas à abordagem dos conceitos físicos que estão diretamente articulados ao tema das mudanças climáticas, podem ser evidenciadas outras perspectivas relativas a essa abordagem.

A primeira questão que pode ser mencionada refere-se ao fato de que o tratamento dos aspectos da complexidade e das controvérsias sobre o tema das mudanças climáticas, que surgem no âmbito científico, pode colaborar para que a visão determinista de ciência seja superada.

O contato com as controvérsias durante as práticas educativas possibilita o distanciamento daquelas concepções de mundo que remetem aos conceitos de harmonia, verdade absoluta, totalidade, determinismo, universo mecânico e neutralidade (SILVA; CARVALHO, 2007). As controvérsias apresentam diversos questionamentos sobre a realidade moderna, induzindo, assim, um pensamento crítico e reflexivo sobre ela.

Neste ensaio, por exemplo, foram apresentadas e discutidas complexidades e controvérsias científicas relativas principalmente ao apontamento das causas para as variações climáticas. Por meio da abordagem desses aspectos, o professor de física colabora para a desmistificação de uma ciência vista como neutra, não controversa e isenta de valores. Isso ocorre já que, para o entendimento dos aspectos da complexidade relativos à temática ambiental, o sujeito envolvido "[...] precisa rever o paradigma da simplificação e compreender o sentido dos resultados, das medidas e das previsões dos modelos utilizados" (RIBEIRO; KAWAMURA, 2014, p. 164).

Entretanto, deve-se estar atento ao fato de que a intenção, ao abordar essas controvérsias científicas, não é a de indicar se o ser humano é ou não responsável pelas mudanças climáticas ou se algumas previsões e discussões científicas sobre 
o tema estão certas ou erradas. Assim como Ribeiro e Kawamura (2014, p.165), considera-se neste trabalho que esse "[...] formato induz a pensar as controvérsias de forma muito maniqueísta, do tipo branco ou preto, sem que os variados tons e nuances de cinza possam ser valorizados". Nesse caso, é pertinente esclarecer que reconhecer as controvérsias que envolvem o tema "mudanças climáticas" não significa a adesão de um posicionamento "contra ou a favor", mas sim reconhecer as complexidades que envolvem essas discussões.

Outro ponto que vale ser destacado refere-se à importância de valorizar o conhecimento científico e seus avanços para a humanidade. O trabalho com as controvérsias científicas e com os aspectos complexos do fenômeno das mudanças climáticas nas aulas de física possibilita o entendimento de que o conhecimento científico é sempre válido e indispensável. Dessa forma, a discussão não deve ser reduzida unicamente a elencar culpados para as variações climáticas atuais ou a aderir a teorias científicas que, dependendo da escolha das hipóteses, possam ser consideradas certas ou erradas.

É necessário desenvolver a ideia de que a ciência apresenta modelos e formas de pensar que são indispensáveis em processos de tomada de decisão que envolvem riscos iminentes. Por esse motivo, a abordagem do fenômeno em questão através de seus aspectos complexos e controversos fornece aos educandos a oportunidade de compreender o sentido das previsões, a fim de tomar decisões conscientes que evitem tanto o desenvolvimento de uma visão unicamente catastrófica sobre o assunto quanto a negação dos impactos que a atividade antrópica tem causado no meio ambiente.

Frente ao reconhecimento de um sistema climático complexo, os professores de física têm ainda a oportunidade de destacar a seus alunos aspectos relativos à impossibilidade de que sejam feitas quaisquer previsões que retratem exatamente o comportamento futuro do sistema climático. Tal sistema, como já explorado em tópicos anteriores, é constituído por inúmeros subsistemas que interagem mutuamente, o que leva ao tratamento de probabilidades e não de certezas absolutas.

Outra perspectiva do trabalho com o tema em questão remete diretamente à ideia de que a abordagem de seus aspectos complexos e controversos contribui de maneira eficaz para a promoção de algumas habilidades e atitudes que colaboram diretamente para a formação de cidadãos críticos e reflexivos frente à realidade posta.

A partir desse entendimento, as propostas de ensino de física que envolvem o fenômeno das mudanças climáticas podem colaborar para o desenvolvimento de uma "[...] visão complexa de mundo e um posicionamento crítico e reflexivo frente às questões socioambientais" (WATANABE-CARAMELLO, 2012, p. 52), visão essa que tem como principal pressuposto a formação de indivíduos que, criticamente, saibam avaliar, tomar decisões e até mesmo promover mudanças nas esferas social, política e econômica. Além disso, tal perspectiva contribui para a elaboração de uma visão na qual o ser humano possa ver-se como parte integrante da natureza.

Diante dessa perspectiva considera-se que a abordagem de complexidades e controvérsias relacionadas ao tema das mudanças climáticas em aulas de física pode 
possibilitar a promoção de

[...] uma mudança nos discursos da ciência escolar, que se propõem em geral neutros e acríticos, de modo que haja uma problematização dos fenômenos naturais pautados na realidade complexa. Isso significa, por exemplo, considerar as dificuldades encontradas pela ciência ao discutir sistemas complexos, abertos e dinâmicos, como é o caso da maioria das relações estabelecidas no sistema terrestre e dos limites de previsibilidade acerca do comportamento desses sistemas (WATANABE-CARAMELLO; KAWAMURA, 2014, p. 260).

Neste artigo evidenciam-se também alguns aspectos complexos e controversos relativos a outros âmbitos que vão além do científico, que são essenciais para a promoção de uma visão complexa do mundo. Essa característica apresenta outras possibilidades para o trabalho com o tema "mudanças climáticas" na sala de aula.

O entendimento de que os problemas ambientais também interferem e sofrem interferências de outras esferas (econômica, política, cultural e social) contribui para a compreensão das diversas relações que podem ser estabelecidas entre os distintos níveis sociais, de modo a compreender que as partes estão em função do todo, assim como o todo está relacionado com as partes. Além disso, reforça a perspectiva de trabalhos interdisciplinares, sobretudo na educação básica.

O destaque para as controvérsias de natureza política, econômica e social relativas a esse fenômeno contribui para o reconhecimento dos conflitos de interesses e das diferentes concepções sobre natureza e ambiente por parte dos agentes que constituem as demais esferas. Nesse sentido, para Watanabe-Caramello e Kawamura (2014), a incorporação da visão complexa e conflituosa das questões ambientais culminaria em uma mudança de pensamento, sendo esta:

[...] requer uma atitude antirreducionista, que possa identificar o discurso dogmático, a utilização de linguagens simplificadoras e reducionistas diante de situações complexas, que saiba lidar com as incertezas, paradoxos e contradições. Cabe destacar que essa mudança de pensamento também implicará rever a relação ser humano/ natureza, de forma que os humanos se reconheçam, não como detentores de meios para o uso e dominação sobre a natureza, mas como parte dos processos e interações históricos que se estabelecem. (WATANABE-CARAMELLO; KAWAMURA, 2014, p. 260)

De acordo com Silva (2007, p. 76), a abordagem dos temas controversos no planejamento e na execução de trabalhos educativos envolvendo a física "[...] traduz-se numa tentativa de evitar abordagens ingênuas da temática ambiental", já que possibilita o entendimento das subjetividades, das incertezas, dos conflitos, dos valores, dos questionamentos metafísicos e políticos envolvidos com as questões ambientais, situação que, de acordo com Leff (2002), é essencial para a emergência da complexidade e do saber ambiental.

Levando em consideração esses argumentos, entende-se que o trabalho educativo que articule a física com os fenômenos climáticos deve constituir-se como um empreendimento amplo, que proporcione uma visão abrangente sobre a temática ambiental e que, ao mesmo tempo, colabore para a formação de cidadãos aptos a 
opinar criticamente sobre questões relacionadas ao meio ambiente e a reconhecer as controvérsias e as complexidades a ele relacionadas.

Com essas reflexões, é possível constatar que as complexidades associadas ao fenômeno das mudanças climáticas podem trazer diversas contribuições para o ensino dos conteúdos específicos da física, já que elas permitem aos professores desenvolverem um trabalho de cunho conceitual por fornecerem a oportunidade de abordar diversos conceitos ligados à Termodinâmica. Ao mesmo tempo, o referido fenômeno fornece elementos tanto para rever concepções sobre a natureza da ciência, quanto para uma compreensão mais abrangente sobre a realidade, privilegiando o destaque de uma visão complexa de mundo e de uma articulação entre os fenômenos naturais e da intervenção de origem antrópica que interferem diretamente no clima terrestre. Por fim, este fornece uma possibilidade rica para os professores de física desenvolverem trabalhos de educação ambiental.

Essas características indicam as articulações que podem ser estabelecidas entre a física e o fenômeno das mudanças climáticas, o que leva a refletir sobre a importância da articulação entre essa área do conhecimento e os fenômenos ambientais.

\section{CONSIDERACְÕES FINAIS}

As ideias desenvolvidas neste ensaio teórico permitiram apresentar algumas reflexões sobre as relações entre a física e a temática ambiental. De modo especial, foi enfatizada a possibilidade de trabalhos educativos a partir do reconhecimento das complexidades associadas aos fenômenos ambientais, especialmente o das mudanças climáticas.

O fenômeno das mudanças climáticas foi apresentado, sobretudo, por retratar o caráter complexo do clima. A abordagem do fenômeno pode trazer grandes contribuições para as práticas educativas de física, no sentido de fazer com que os estudantes entrem em contato com sua complexidade, colaborando para a construção de uma visão mais reflexiva sobre o tema, bem como para a compreensão e a identificação das controvérsias suscitadas pelas discussões que circundam o fenômeno.

Ressalta-se que muitos discursos sobre a questão climática deixam de lado essas reflexões e se concentram em manifestações alarmistas e pouco fundamentadas cientificamente sobre as causas e as origens das mudanças climáticas, retratando a interação entre ser humano e natureza como a única causa para o fenômeno, sugerindo que as consequências dessa interação possam ser revertidas. Em outro extremo, os céticos indicam que a dinamicidade climática impossibilita que a atividade humana sobre a natureza seja apresentada como causa predominante das mudanças climáticas e, para muitos, essa interação pode até mesmo ser negligenciada.

Nesse sentido, diferente de um discurso extremista e restrito à fragmentação entre esses posicionamentos em relação à questão ambiental, é necessário olhar para os fenômenos climáticos de forma desafiadora, afinal, o desafio que se coloca 
é como tratar e lidar com essas incertezas frente à complexidade das questões ambientais, que envolvem diretamente aspectos não apenas de natureza científica, mas também política, econômica e social.

Durante o trabalho educativo com o tema "mudanças climáticas", esse aspecto deve ser elucidado, a fim de que as propostas educativas não sejam reduzidas ao exercício de elencar o que é certo ou errado ou o que pode ser desconsiderado. Essa perspectiva de trabalho com a temática ambiental colocaria todos os envolvidos frente a uma ciência neutra, balizada por certezas e possibilidades de previsões determinísticas sobre esse fenômeno, que é livre de valores e está fora do alcance de outras esferas da sociedade.

Por esse mesmo motivo, torna-se necessário colocar todos diante da complexidade do fenômeno para que essas controvérsias, os pontos de desacordo e as discussões sobre a temática sejam devidamente compreendidos pelos educandos. É importante ainda esclarecer que, diante da complexidade do fenômeno, convive-se em uma sociedade de risco, fato que implica diretamente a necessidade de que escolhas sejam feitas. Nessa perspectiva, a responsabilidade da gestão dos riscos não deve estar restrita apenas aos cientistas e aos governantes, mas deve ser compartilhada por toda a sociedade.

Dessa forma, o fato de se considerarem controvérsias e complexidades inerentes ao fenômeno em questão não impede de reconhecer os impactos negativos que as atividades antrópicas têm causado sobre o meio ambiente. Esses impactos socioambientais apresentam justificativas suficientes para se repensar a relação do ser humano com a natureza, com a sociedade e consigo mesmo de modo a reconhecer o que de fato é urgente e necessário.

O que se propõe com essa reflexão, sempre reconhecendo e reforçando a necessidade de processos de tomada de decisão que minimizem os riscos futuros relacionados às mudanças no clima, é ponderar que não é possível levar em consideração apenas um único ponto de vista ou fator que interfira diretamente nas mudanças climáticas e que as relações entre esses diversos elementos (tanto naturais, quanto antrópicos) apresentam um futuro climático cercado pela incerteza e pela irreversibilidade.

Sendo assim, conclui-se que os assuntos ligados ao fenômeno das mudanças climáticas têm muito a contribuir para o ensino de ciências, em particular o de física. Esse fato aponta para a necessidade de que os professores dessa disciplina reconheçam os aspectos controversos relacionados ao fenômeno e que eles emergem de uma realidade complexa.

\section{REFERÊNCIAS}

AKASOFU, S. Is the Earth still recovering from the "Little Ice Age"? A possible cause of global warming. International Artic Research Center, Fairbanks, p. 1-14, 2006. Disponível em: < http://www.wright. edu/ guy.vandegrift/climateblog/s06/akasofu.LIAge.pdf>. Acesso em: 15 mar. 2013.

BARBOSA, L. G.; LIMA, M. E. C. C.; MACHADO, A. H. Controvérsias sobre o aquecimento global: circulação de vozes e de sentidos produzidos em sala de aula. Ensaio, Belo Horizonte, v. 14, n. 1, p. 113-130, 2012. Disponível em: <http://www.portal.fae.ufmg.br/seer/index.p 
hp/ensaio/article/viewFile/613/798>. Acesso em: 10 nov. 2012.

CASAGRANDE, A.; SILVA JUNIOR, P.; MENDONÇA, F. Mudanças climáticas e aquecimento global: Controvérsias, incertezas e a divulgação científica. Revista Brasileira de Climatologia, Curitiba, v. 8, p. 30-44, 2011. Disponível em: < http://ojs.c3sl.ufp

r.br/ojs2/index.php/revistaabclima/article/viewFile/25793/17212>. Acesso em: 18 nov. 2012.

FIEDLER-FERRARA JUNIOR, N. Quando o todo é mais sagaz do que a soma de suas partes. Scientle Studia, São Paulo, v. 3, n. 2, p. 323-37, 2005. Disponível em: <http://www.scielo.br/pdf/ss/v3n2/ a09v3n2.pdf $>$. Acesso em: 10 maio 2013.

HAYS, J. D.; IMBRIE, J.; SHACKLETON, N. J. Variations in the Earth's Orbit: Pacemaker of the Ice Ages. Science, New York, v. 194, n. 4270, p. 1121-1132, 1976. Disponível em: <http://www.mantleplumes.org/WebDocuments/Hays1976.pdf>. Acesso em: 25 fev. 2015.

JACOBI, P. R.; GUERRA, A. F. S.; SULAIMAN, S. N.; NEPOMUCENO, T. Mudanças Climáticas

Globais: a resposta da Educação. Revista Brasileira de Educação, Rio de Janeiro,

v. 16, n. 46, p. 135-268, 2011. Disponível em: <http://www.scielo.br/pdf/rbedu/v16n46/v16 n46a08.pdf> Acesso em: 10 mar 2012.

JURAS, I. A. G. M. Aquecimento global e mudanças climáticas: Uma introdução. Plenarium,

Brasília, v. 5, n. 5, p. 34-46, 2008. Disponível em: <http://bd.camara.gov.br/bd/bitstream/handle/ bdcamara/641/aquecimento_global_introducao.pdf?sequence=3> Acesso em: 22 mar. 2012.

LEFF, E. Epistemologia ambiental. 3. ed. São Paulo: Cortez, 2002.

MORIN, E. Introducão ao pensamento complexo. 3 ed. Porto Alegre: Sulina, 2007.

OLIVEIRA, M.; VECCHIA, F. A controvérsia das mudanças climáticas e do aquecimento global antropogênico: consenso científico ou interesse político? In: FÓRUM AMBIENTAL DA ALTA PAUliSTA, 5, 2009. Atas... Fórum Ambiental da Alta Paulista. São Paulo: ANAP, 2009. p. 946-962, 2009. Disponível em: <http://www.fakeclimate.com/arquivos/ArtigosFake/mc-2009-001.pdf>. Acesso em: 10 maio 2012.

PINA, A.; SILVA, L. F.; OLIVEIRA JÚNIOR, Z. T. Mudanças Climáticas: reflexões para subsidiar esta discussão em aulas de Física. Caderno Brasileiro de Ensino de Física. Florianópolis, v. 27, n. 3, p. 449-472, 2010. Disponível em: <http://journal.ufsc.br/index.php/fisica/article/view/2175-7941.2010v27n3p449/17182>. Acesso em: 5 dez. 2012.

PRIGOGINE, I. O fim das certęas: tempo, caos e as leis da natureza. Tradução de Roberto Leal Ferreira. São Paulo: Unesp, 1996.

PRIGOGINE, I. As leis do caos. Tradução de Roberto Leal Ferreira. São Paulo: Unesp, 2002.

PRIGOGINE, I; STENGERS, I. A nova aliança. Brasília: Universidade de Brasília, 1984.

REIS, D. A. Compreensões elaboradas pelo campo da educaşão ambiental sobre o tema mudanças climáticas: análise de dissertações e teses brasileiras. 2013. 217 f. Dissertação (Mestrado em Educação) - Universidade Estadual Paulista Júlio de Mesquita Filho, Rio Claro, Rio Claro, 2013.

REIS, D. A; SILVA, L. F; SILVA, A. P. Algumas compreensões dos licenciandos em Física sobre o fenômeno mudanças climáticas. Alexandria, Florianópolis, v. 4, n. 2, p. 57-81, 2011. Disponível em: <http://alexandria.ppgect.ufsc.br/files/2012/03/Danielle.pdf> Acesso em: 18 nov. 2012.

RIBEIRO, R. A.; KAWAMURA, M. R. D. Educação ambiental e temas controversos. Revista Brasileira de Pesquisa em Educação em Ciências, São Paulo, v. 14, n. 2, 2014, p. 159-169.

SAMPAIO, G.; MARENGO, J. A.; NOBRE, C. A atmosfera e as mudanças climáticas. In: BUCKE- 
RIDGE, Marcos (Org.). Biologia e mudanças climáticas no Brasil, São Paulo, 2008, p. 23-46.

SANTOS, W. L. P.; CARVALHO, L. M.; LEVINSON, R. A dimensão política da educação ambiental em investigações de revistas brasileiras de ensino de ciências. Revista Brasileira de Pesquisa em Educação em Ciências, São Paulo, v. 14, n. 2, 2014, p. 199-2013.

SILVA, C. N.; LOBATO, A. C.; LAGO, R. M.; CARDEAL, Z. L.; QUADROS, A. L. Ensinando a química do efeito estufa no Ensino Médio: possibilidades e limites. Química Nova na Escola, São Paulo, v. 31, n. 4, 2009, p. 268-274.

SILVA, L. F. A temática ambiental, o processo educativo e os temas controversos: implicações teóricas e práticas para o ensino de Física. 2007. 213 f. Tese (Doutorado em Educação) - Universidade Estadual Paulista Júlio de Mesquita Filho, Araraquara, Araraquara, 2007.

SILVA, L. F.; CARVALHO, L. M. A temática ambiental e o processo educativo:o ensino de física a partir de temas controversos. Ciência \& Ensino, Piracicaba, v. 1, número especial, nov. 2007.

VEIGA, J. E.; VALE, P. M. Aquecimento global: um balanço das controvérsias. Texto apresentado no ciclo de seminários do Departamento de Economia da FEA/USP intitulado "Brasil no Século XXI: Desafios do Futuro", São Paulo, p. 1-52, 2007.

VIEIRA, K. R. C. F.; BAZZO, W. A. Discussões acerca do aquecimento global: uma proposta CTS para abordar esse tema controverso em sala de aula. Ciência \& Ensino, Piracicaba, v. 1, número especial, 2007.

WATANABE-CARAMELLO, G.; KAWAMURA, M. R. D. Uma abordagem termodinâmica para discutir a física do meio ambiente. In: ENCONTRO DE PESQUISA EM ENSINO DE FÍSICA, 7, 12., 2010, Águas de Lindoia. Atas... São Paulo: SBF, 2010. p. 1- 13.

WATANABE-CARAMELLO, G.; KAWAMURA, M. R. D. Uma educação na perspectiva ambiental crítica, complexa e reflexiva. Revista Brasileira de Pesquisa em Educação em Ciências, Belo Horizonte, v. 14, n. 2, 2014, p. 255-264.

WATANABE-CARAMELLO, G. Aspectos da complexidade: contribuições da física para a compreensão do tema ambiental. 2012. 246 f. Tese (Doutorado em Ensino de Ciências) - Instituto de Física e Faculdade de Educação, Universidade de São Paulo, São Paulo, 2012.

XAVIER, M. E.; KERR, A. S. A análise do efeito estufa em textos paradidáticos e periódicos jornalísticos. Caderno Brasileiro de ensino de Física, Florianópolis, v. 21, n. 3, p. 325-349, 2004. Disponível em: $<$ http://www.cetesb.sp.gov.br/userfiles/file/mudancasclimaticas/proc

$\operatorname{lima/file/publicacoes/conceitos/portugues/analisedoefeitoestufaemtextosjornalisticos.pdf~>~.~Acesso~}$ em: 10 maio 2012.

Data do recebimento: 15/06/2014

Data da aprovação: 24/03/2015

Data da versão final: $30 / 11 / 2015$

\section{Contato:}

Danielle Aparecida dos Reis

Universidade Estadual Paulista Júlio Mesquita Filho

Avenida 24 A, 1515 - Bela Vista

13506-900 Rio Claro - SP, Brasil

Email: dani_aparecidareis@yahoo.com.br 